\title{
GERENCIANDO A DIVERSIDADE CULTURAL: experiências de empresas brasileiras
}

Maria Tereza Leme Fleury

Mestre e Doutora em Sociologia pela Universidade de São Paulo (USP), Livre-Docente em Administração pela USP, Vice-Diretora e Professora Titular da FEA (USP) e Editora da RAUSP.

E-mail:mtfleury@usp.br

\section{RESUMO}

Apesar do contexto cultural diversificado em que atuam as empresas brasileiras, o tema diversidade cultural é recente em sua agenda. Surge em subsidiárias de empresas americanas, em um primeiro momento, por pressão da matriz e, em seguida, ligado à necessidade de criar vantagens competitivas desenvolvendo competências diversas; não acontece por imposição legal, como ocorre nos EUA e no Canadá. Partindo da elaboração de um referencial conceitual sobre diversidade cultural e seu gerenciamento, este artigo apresenta os resultados obtidos por meio de uma pesquisa realizada com empresas brasileiras e mediante um estudo de caso mais aprofundado.

\section{ABSTRACT}

Despite the extremely diversified cultural context in which Brazilian enterprises operate, the issue of cultural diversity is new in their agen$d a$. The emergence of this theme is much more related to the need to create competitive advantages by developing diversified competencies, usually following policies which are established by the headquarters of local subsidiaries, instead of attending to legal procedures, as in the USA and Canada. Departing from a conceptual elaboration about cultural diversity and its management, this article presents the results achieved in a research among leading Brazilian firms. The points that emerge as a conclusion can be generalized for other countries.

PALAVRAS-CHAVE

Diversidade cultural, administração de recursos humanos, estudos comparativos.

\section{KEY WORDS}

Cultural diversity, human resources management, comparative studies. 


\section{INTRODUÇÃO}

Neste ano, os brasileiros comemoraram os 500 anos de sua existência para o mundo ocidental. O projeto de colonização brasileiro, assim como o da maioria dos países latino-americanos, diferentemente dos Estados Unidos e do Canadá, fundamentou-se sobre o binômio exploração da riqueza tropical (cana-deaçúcar, madeira, minerais e café) e exploração do trabalho escravo (no início, os índios nativos e, mais tarde, os negros trazidos da África).

Durante o século XIX, o Brasil passou por transformações significativas em termos políticos (Independência, instauração da Monarquia e, finalmente, a proclamação da República) e em termos econômicos (com o processo de industrialização e urbanização da Região Sudeste do país). Culturalmente, o país também sofreu mudanças, com a vinda de imigrantes europeus e asiáticos. Esses imigrantes tinham um nível educacional superior ao da população local e, principalmente no caso dos italianos e espanhóis, tradição de lutas políticas ligadas ao anarquismo.

Ao longo da História, determinados padrões culturais foram se desenvolvendo no país, como resultado da formação de uma população culturalmente diversificada e miscigenada pelos casamentos interraciais. Ao mesmo tempo, foi se constituindo uma sociedade na qual o trabalho manual sempre foi desvalorizado e relegado aos escravos e à população de baixa renda. Com os processos de industrialização e urbanização, uma classe média mais heterogênea surgiu no cenário brasileiro, mas a desvalorização do trabalho manual permaneceu.

Assim, uma sociedade contraditória foi emergindo. Os brasileiros valorizam sua origem diversificada, incluindo as raízes africanas, presentes na música, na alimentação, no sincretismo religioso; gostam de se imaginar como uma sociedade sem preconceitos de raça ou cor. Mas, por outro lado, é uma sociedade estratificada, em que o acesso às oportunidades educacionais e às posições de prestígio no mercado de trabalho é definido pelas origens econômica e racial.

Neste contexto diversificado e contraditório, o tema diversidade cultural é relativamente novo na agenda das empresas brasileiras. Surge no bojo dos processos de mudança, vivenciados pelas empresas no ambiente altamente competitivo dos anos 90; aparece, também, em empresas subsidiárias de multina- cionais americanas, em conseqüência de pressões da matriz; não tem origem em dispositivos legais, como ocorre em outros países, como os Estados Unidos e Canadá.

Este artigo objetiva trazer o tema da diversidade cultural em empresas brasileiras para a pauta das discussões. Iniciando com uma breve recuperação conceitual, apresentaremos os resultados de uma pesquisa empírica com empresas brasileiras.

Os brasileiros valorizam sua origem diversificada, incluindo as raízes africanas, presentes na música, na alimentação, no sincretismo religioso. Mas é uma sociedade estratificada, em que 0 acesso às oportunidades educacionais e às posições de prestígio no mercado de trabalho é definido pelas origens econômica e racial.

\section{CONCEITUALIZANDO A DIVERSIDADE CULTURAL}

A questão das minorias e da diversidade cultural tem sido um tema relevante nos países da América do Norte - EUA e Canadá. Desde a década de 60, os movimentos políticos a favor da integração racial levaram à promulgação de leis visando à igualdade de oportunidades de educação e ao emprego para todos.

Nos EUA, o Affirmative Action foi promulgado no final da década de 60 como resposta à discriminação racial observada nas empresas e instituições de ensino. Por regulamentação federal, as empresas que tinham contratos com o governo ou que dele recebiam recursos e benefícios deviam avaliar a diversidade existente em seu corpo de funcionários e procurar balancear sua composição, em face da diversidade existente no mercado de trabalho. Esses grupos incluíam: mulheres, hispânicos, asiáticos e índios (deficientes físicos foram incluídos após 1991) (Agócs e Burr, 1996, p. 32).

No Canadá, o Employment Equity Act e o Federal Contractors Program, promulgados em 1986, foram delineados nos moldes do Affirmative Action norteamericano. De acordo com Agócs e Burr (1996), essas leis visavam a ampliar o espaço das minorias, não somente aumentando e melhorando a representação 
numérica, por meio do sistema de cotas nas empresas, mas também promovendo relações mais eqüitativas e justas de emprego.

Em artigo recente, Jain (1998), avaliando esses programas em diferentes países (EUA, Canadá, Índia, Malásia, África do Sul, Grã-Bretanha e Irlanda do Norte), concluiu que o crescimento econômico é um pré-requisito para o sucesso de tais programas e que a legislação é uma condição necessária, mas não suficiente, para o seu êxito.

ral pode ser estudado sob diferentes perspectivas: no nível da sociedade, no nível organizacional e no nível do grupo ou indivíduo. Os padrões culturais, expressando valores e relações de poder, precisam ser referenciados e analisados em todos os níveis.

Segundo Thomas (1996), a gestão da diversidade cultural implica adotar um enfoque holístico para criar um ambiente organizacional que possibilite a todos o pleno desenvolvimento de seu potencial na realização dos objetivos da empresa. Não é um pacote com soluções prontas nem um programa para resolver a questão da discriminação e do preconceito.

Cox (1994) assume que as diferenças de identidade individuais (tanto físicas quanto culturais) interagem com uma complexa gama de fatores individuais, grupais e organizacionais (o clima da diversidade) para determinar o impacto da diversidade nos resultados individuais e organizacionais. Os resultados individuais são divididos em variáveis de resposta afetiva (satisfação,

Com um enfoque mais pragmático, a gestão da diversidade cultural foi uma resposta empresarial à diversificação crescente da força de trabalho e às necessidades de competitividade. Em 1985, os dados projetados por estudos do Instituto Hudson para o ano 2000 estimaram uma força de trabalho para os EUA com diferentes características: os brancos diminuiriam sua participação no mercado de trabalho, e o segmento mulheres brancas aumentaria, seguido por homens e mulheres negros.

Subbarao (1995) notou que a diversidade da força de trabalho é um fenômeno internacional, presente nos países desenvolvidos ou em desenvolvimento. Há diversos aspectos a serem considerados ao se pensar no que significa diversidade: sexo, idade, grau de instrução, grupo étnico, religião, origem, raça e língua. Mamman (1995) e Nilson (1997) assumem também que o conceito de diversidade cultural inclui não somente a raça e o sexo mas também grupos étnicos, região de origem, idade, etc.

Como conceitualizar a diversidade cultural? A diversidade é definida como um mix de pessoas com identidades diferentes interagindo no mesmo sistema social. Nesses sistemas, coexistem grupos de maioria e de minoria. Os grupos de maioria são os grupos cujos membros historicamente obtiveram vantagens em termos de recursos econômicos e de poder em relação aos outros.

Verificamos, assim, que o tema diversidade cultu- identificação organizacional e envolvimento no trabalho) e em variáveis de desempenho (performance, mobilidade no cargo e compensação). Os resultados organizacionais podem impactar o nível de atendimento, de turnover, de qualidade do trabalho e de lucratividade.

Central a essa proposta é a noção de que a diversidade presente nas organizações provocará impactos tanto em termos da eficácia organizacional como individual e de que o contexto organizacional é relevante para determinar se esse impacto será positivo ou negativo. Outra característica da proposta é o fato de que ela está estruturada sobre dimensões psicológicas e sociais, que têm clara aplicabilidade nas várias dimensões da identidade de grupo (por exemplo, não só sexo e raça, mas nacionalidade, descrição do cargo, religião, classe e assim por diante) e são aplicáveis à experiência de membros de ambos os grupos: maioria e minoria nas organizações. Notamos, por exemplo, que o não-gerenciamento da diversidade pode conduzir a forte conflito intergrupal entre membros da maioria e da minoria, reduzindo os resultados efetivos do trabalho para homens de ambos os grupos (Knomo e Cox, 1996).

Segundo Cox, a administração da diversidade cultural significa planejar e executar sistemas e práticas organizacionais de gestão de pessoas de modo a maximizar as vantagens potenciais da diversidade e minimizar as suas desvantagens (Cox, 1994, p. 11). 
A nosso ver, é necessário acrescentar ainda mais uma dimensão: administrar a diversidade significa adicionar valor à organização.

Entre os benefícios potenciais da gerência da diversidade, Cox menciona os seguintes:

- atrair e reter os melhores talentos no mercado de trabalho;

- desenvolver os esforços de marketing, visando a atender segmentos de mercado diver-

sificados;

- promover a criatividade e a inovação;

- facilitar a resolução de problemas;

- desenvolver a flexibilidade organizacional.

Em suma, o objetivo principal da gestão da diversidade cultural é administrar as relações de trabalho, as práticas de emprego e a composição interna da força de trabalho a fim de atrair e reter os melhores talentos dentre os chamados grupos de minoria. Isso pode ser feito por políticas de recrutamento que incorporem os critérios relacionados à diversidade cultural do mercado de trabalho.

Entretanto, como mudar os padrões culturais dominantes em uma organização? Que políticas e práticas para a gestão de pessoas devem ser implementadas para isso? A realização de uma pesquisa entre empresas brasileiras propiciou pistas interessantes para discutirmos essas questões.

\section{ADMINISTRAÇÃO DA DIVERSIDADE NAS ORGANIZAÇÕES BRASILEIRAS}

O tema da desigualdade racial e sexual tem sido objeto de intensa discussão no Brasil, levada adiante por grupos defensores dos negros, mulheres e homossexuais. Os debates atingem mais a mídia, repercutindo sobre as esferas governamentais, com poucas medidas concretas, entretanto, sendo tomadas a respeito.

Em 1996, foi criado o Programa Nacional de Direitos Humanos, visando à implementação de atos e declarações internacionais relacionados aos direitos humanos e contando com a adesão brasileira. Uma delas é a Convenção 111 da OIT sobre a discriminação nas relações de emprego, ratificada pelo governo local em 1965. Foi somente em 1995 que o governo brasileiro, enquanto participava da Conferência ILO, enfrentando acusações apresentadas por representantes dos trabalhadores brasileiros a respeito do nãocumprimento de compromissos assumidos por empresas locais, solicitou cooperação técnica ao ILO para a formulação e implementação efetiva de políticas para promover a igualdade nas oportunidades de emprego e no tratamento (Ministério do Trabalho do Brasil, 1996).

Verificamos, assim, que medidas governamentais para combater a discriminação no emprego são muito recentes. A nosso ver, esbarram em uma barreira cultural implícita: a não-aceitação do preconceito e da discriminação racial. Como já mencionamos, o Brasil é um país he-

\section{Como mudar os padrões culturais dominantes} em uma organização? Que políticas e práticas para a gestão de pessoas devem ser implementadas para isso? A realização de uma pesquisa entre empresas brasileiras propiciou pistas interessantes para discutirmos essas questões.

terogêneo, fruto de inúmeros fluxos imigratórios desde o momento de sua formação; faz parte da ideologia nacional conceber-se como um país sem preconceitos.

$\mathrm{O}$ interesse das empresas brasileiras na gestão da diversidade cultural é também recente, surgiu nos anos 90. A grande maioria das companhias que estão desenvolvendo programas são subsidiárias de empresas norte-americanas.

Visando à melhor compreensão desse tema, não somente de um ponto de vista acadêmico mas também para subsidiar trabalhos de intervenção, realizamos uma pesquisa exploratória em empresas brasileiras. Três perguntas orientaram o desenho da pesquisa:

- Quais as origens do programa de gestão da diversidade cultural e como este foi implementado na empresa?

- No caso das subsidiárias, quais eram as diferenças entre os programas implementados nas matrizes e os desenvolvidos nas empresas brasileiras?

- Quais eram as principais políticas e práticas efetivamente implantadas para o gerenciamento da diversidade cultural?

Em termos de procedimentos metodológicos, alguns esclarecimentos são necessários: para realizar a pesquisa, foram contatadas 15 empresas, que, por meio de seminários e da mídia, divulgavam estar desenvolvendo programas de administração da diversidade cultural. Destas, somente 7 concordaram em nos receber para conversar sobre o programa; as outras não quiseram participar da pesquisa, alegando que seu 
programa era ainda muito embrionário ou inoperante.

Inicialmente, apresentaremos os dados coletados em seis das empresas; nestas, entrevistamos o gerente responsável pelo programa e coletamos as informações disponíveis em documentos. O último caso apresentado diz respeito a uma empresa na qual estamos desenvolvendo um projeto com o uso da metodologia de pesquisa-ação, objetivando a implementação de um programa de diversidade cultural; a discussão mais detida desse caso traz alguns insights interessantes sobre o tema.
No primeiro grupo, cinco das empresas pesquisadas são subsidiárias de multinacionais norte-americanas e uma delas é brasileira. Os projetos desenvolvidos pelas empresas estão ainda em sua fase inicial. As subsidiárias estão monitorando o que ocorre nas matrizes, em termos de políticas e práticas, e, então, avaliando sua aplicabilidade e possível adaptação à realidade brasileira.

O Quadro 1 sintetiza os principais dados coletados. Algumas observações podem ser feitas a partir desse quadro:

Quadro 1 - A gestão da diversidade em equipes no Brasil

\begin{tabular}{|c|c|c|c|}
\hline ÁREA & N. DE EMPR. & CONCEITO DE DIVERSIDADE & PRÁTICAS DE DIVERSIDADE \\
\hline $\begin{array}{l}\text { Computadores/ } \\
\text { comunicação }\end{array}$ & 778 & $\begin{array}{l}\text { - Foco: locais de trabalho não excludentes. } \\
\text { - Matriz } \Rightarrow \text { Diversidade significa não-discriminação. } \\
\text { Uso de dados e indicadores quantitativos } \\
\text { sobre a composição dos empregados. } \\
\text { - Cada subsidiária desenvolve seu próprio programa. }\end{array}$ & $\begin{array}{l}\text { - Apesar de não haver nenhuma política de } \\
\text { recrutamento que vise explicitamente a aumentar } \\
\text { a diversidade, a força de trabalho é diversificada. } \\
\text { - Identificação e eliminação das barreiras à } \\
\text { promoção de carreira. }\end{array}$ \\
\hline Química & 1.531 & $\begin{array}{l}\text { - A diversidade é considerada uma questão } \\
\text { estratégica para se obter vantagem competitiva. } \\
\text { - Conceito global - prática local. } \\
\text { - Matriz } \Rightarrow \text { Políticas de diversidade bem desenvolvidas } \\
\text { incluem raça e gênero. } \\
\text { Uso de dados e indicadores quantitativos } \\
\text { sobre a composição dos empregados. }\end{array}$ & $\begin{array}{l}\text { - A abordagem da diversidade está apenas focada } \\
\text { - Tre mulher. } \\
\text { - Iniciando programas internos de treinamento. } \\
\text { - Comunicação sobre programas de diversidade. } \\
\text { - Políticas de recrutamento e carreira: em relação } \\
\text { à mulher. }\end{array}$ \\
\hline Têxtil & 600 & $\begin{array}{l}\text { - Respeito pelas diferenças. } \\
\text { - Matriz } \Rightarrow \text { Um programa em curso por longo tempo e } \\
\text { bem desenvolvido inclui raça, gênero e } \\
\text { homossexuais. } \\
\text { - Conceito global - prática local. }\end{array}$ & $\begin{array}{l}\text { - Iguais oportunidades para negros e mulheres. } \\
\text { Promoções e carreira são, no entanto, } \\
\text { primariamente focadas na mulher. } \\
\text { - Programas de treinamento sobre diversidade. } \\
\text { - Comunicação interna sobre programas de } \\
\text { diversidade. }\end{array}$ \\
\hline Eletrônica & 6.500 & $\begin{array}{l}\text { - A diversidade é definida não só pela raça e pelo } \\
\text { sexo mas também pela idade e pelo perfil cultural. } \\
\text { - Matriz } \Rightarrow \text { Velho e desenvolvido programa. }\end{array}$ & $\begin{array}{l}\text { Os programas de participação nos lucros } \\
\text { incluem todos os empregados. } \\
\text { - O planejamento administrativo da carreira tem } \\
\text { de indicar mulheres e negros. }\end{array}$ \\
\hline Química & 1.200 & $\begin{array}{l}\text { - Curso de dupla ação: reconhecer a diversidade } \\
\text { entre os empregados. } \\
\text { - As vantagens competitivas vêm da diversidade e } \\
\text { do talento dos funcionários. } \\
\text { - Matriz } \Rightarrow \text { Programa bem desenvolvido. } \\
\text { - Política e programas culturais. }\end{array}$ & $\begin{array}{l}\text { - Subsidiárias de Los Angeles estão estudando } \\
\text { como implementar o programa de diversidade } \\
\text { da matriz. }\end{array}$ \\
\hline Cosméticos & 3.000 & $\begin{array}{l}\text { - Uma força de trabalho diversificada é uma } \\
\text { vantagem competitiva. } \\
\text { - Matriz (brasileiro). }\end{array}$ & $\begin{array}{l}\text { Políticas de recrutamento visando a uma força } \\
\text { de trabalho diversificada. } \\
\text { - Desenvolvimento de oportunidades de carreira } \\
\text { para todos os funcionários. }\end{array}$ \\
\hline
\end{tabular}


- políticas de recrutamento e pessoal de seleção: as empresas estão investindo em projetos para diversificar sua força de trabalho, focando prioritariamente a questão do gênero; em outras palavras, estão recrutando mais mulheres, para balancear seu corpo de empregados. Uma das empresas está incluindo também negros em sua estratégia de diversificação;

- políticas de treinamento: as empresas têm enviado seus gerentes para programas de treinamento para conscientização das diferenças culturais. Apenas uma das empresas pesquisadas investiu na realização de programas aqui a esse respeito;

- comunicação: as companhias estão investindo em projetos de comunicação interna, com a finalidade de divulgar os objetivos do programa de diversidade a todos os empregados.

Essas empresas estão tentando desenvolver um enfoque próprio, adaptado à realidade brasileira. A decisão de começar o programa pelas mulheres, aumentando a participação feminina na composição do corpo de funcionários, é justificada pelo fato de a mulher se encontrar disponível nas diversas profissões. Negros são considerados mais difíceis de ser encontrados para ocupações que demandem níveis educacionais mais elevados, refletindo as desigualdades presentes na sociedade brasileira. No entanto, mesmo que nos últimos anos tenham existido claras evidências da ascensão educacional da mulher, acreditamos que as barreiras culturais à incorporação das mulheres em organizações brasileiras são menores que as barreiras à incorporação dos negros. A avaliação de pessoas de origem asiática é ambígua: elas são consideradas geralmente bem-educadas e, algumas vezes, são tratadas como grupos de minoria.

Em síntese, o conceito da diversidade cultural adotado por essas companhias é ainda bastante restrito, incorporando apenas o gênero e, timidamente, a raça.

\section{O caso da companhia ALPHA}

A ALPHA é subsidiária de uma companhia norteamericana. Tem duas plantas no Brasil, uma no setor de equipamentos e outra no setor químico.

A matriz da empresa se encontra nos EUA, e as filiais, em 22 países; emprega 17 mil pessoas em aproximadamente 100 plantas ao redor do mundo, com um faturamento de US\$ 6 bilhões. A empresa começou suas atividades nos EUA em fins do século
XIX, na produção e comercialização de equipamentos agrícolas.

A empresa investe em tecnologia e, nos últimos anos, tem realizado diversas aquisições visando a ampliar sua participação no mercado global. Em termos de gestão de recursos humanos, é uma empresa qualificada como mais para conservadora, pelos padrões americanos; as subsidiárias têm autonomia para desenvolver seus próprios modelos. Realiza, globalmen- te, uma pesquisa bianual sobre o clima organizacional, procurando monitorar as percepções e expectativas dos empregados.

No Brasil, a empresa tem operado desde os anos 70 , com as duas plantas na Região Sudeste do país. O faturamento anual é de US\$ 170 milhões, e a empresa emprega aproximadamente 500 pessoas. A missão da companhia no Brasil é "ser reconhecida como um centro de excelência no setor agrícola" e as competências de seus empregados são consideradas fundamentais para alcançar seus objetivos. A área de Recursos Humanos desempenha um papel importante nessa estratégia.

$\mathrm{Na}$ década de 80, a empresa fornecia equipamentos para o governo americano e começou a elaborar um programa de diversidade cultural, de cunho bem legalista, no enfoque do Affirmative Action. Nos anos 90, foi criado o Corporate Council of Minorities, e a diversidade começou a ser considerada parte da estratégia dos negócios, a ser divulgada como um valor importante para toda a empresa.

Para a ALPHA, o conceito de diversidade cultural engloba os seguintes aspectos:

- reconhecimento de que pessoas de origens diferentes têm talentos e habilidades diferentes e que podem contribuir para o crescimento da empresa;

- respeito pelo indivíduo, independentemente de raça, sexo, religião ou origem;

- criação de possibilidades para o desenvolvimento 
do negócio e das carreiras dos empregados, livre de preconceitos.

Nos EUA, as principais estratégias definidas para administrar a diversidade foram:

- comunicação do programa;

- desenvolvimento de liderança;

- políticas de recrutamento e seleção.

Um manual foi elaborado como guia para a implementação do programa pelas subsidiárias. A ALPHA do Brasil foi a primeira companhia do grupo a procurar implementar o programa fora dos EUA. O principal executivo da subsidiária brasileira participou das atividades do Corporate Council of Minorities e trouxe o manual visando à sua tradução e adaptação à realidade brasileira.

Durante um workshop interno envolvendo os dirigentes da empresa, foi decidido que o manual não seria simplesmente traduzido e adaptado (o processo usual de "tropicalização"), mas que eles desenvolveriam seus próprios conceitos e enfoque para trabalhar a diversidade no Brasil. Notou-se que o conceito de diversidade está relacionado, principalmente, ao respeito à individualidade dos empregados e ao reconhecimento desta; gerenciar a diversidade implica o desenvolvimento das competências necessárias ao crescimento e sucesso do negócio. Em outras palavras, administrar a diversidade deve adicionar valor à companhia.

A empresa iniciou um projeto de pesquisa-ação, apoiada por uma consultoria, no qual os diagnósticos deveriam subsidiar a definição de objetivos e ações.

A primeira etapa do projeto foi mapear a composição do quadro de funcionários da empresa. É interessante mencionar que nenhuma das outras firmas brasileiras estudadas possuía dados disponíveis a respeito da composição dos seus empregados em termos de raça, origem, sexo, etc. Os dados coletados da ALPHA do Brasil estão apresentados na Tabela 1.

Essa pesquisa inicial mostrou um retrato muito homogêneo da força de trabalho da companhia. Ela é composta por homens brancos, relativamente jovens, a maioria deles nascidos e educados na região de São Paulo. Acompanhando os processos de seleção, trei- namento e promoções na carreira durante um ano e meio, a empresa verificou que esse perfil se tornou ainda mais acentuado.

Como um segundo passo, uma pesquisa foi conduzida entre os empregados, visando a apreender suas percepções sobre a diversidade cultural. Observou-se que a maioria deles não percebem as políticas de recursos humanos - recrutamento e seleção, treinamento e promoção - como contribuindo para um ambiente culturalmente diversificado; notou-se também que a companhia não investe na formação de equipes diversificadas de trabalho. Os homens brancos se sentem muito mais comprometidos com os objetivos da companhia do que os outros grupos; os negros se sentem mais prejudicados do que outros grupos, principalmente em processos de avaliação de desempenho.

Essas informações causaram surpresa entre os gestores da empresa e confirmaram sua decisão de desenvolver o programa, com estratégias e indicadores próprios.

O ponto principal para a definição do programa foi relacioná-lo às estratégias de negócios e ao desenvolvimento de competências, ou seja, a empresa almeja ter uma política de valorização da diversidade visando a atrair, reter e desenvolver os melhores talentos, quebrando as barreiras de gênero e origem, além de introduzir práticas que facilitem o trabalho em equipes diversas e a rotação das pessoas entre áreas e unidades.

Duas linhas de trabalho foram, assim, desenvolvendo-se na empresa: uma mais convencional, como recrutar mulheres com formação em agronomia para a área comercial, uma vez que elas podem trazer contribuições relevantes a essa função; recrutar também pessoas em outras regiões do país, e não somente de São Paulo; programar a rotação interna da área administrativa à operacional e entre unidades; formar equipes heterogêneas, por exemplo, na área de $\mathrm{P} \& \mathrm{D}$ para desenvolvimento de produtos. A outra linha foi com o propósito de rever os objetivos estratégicos, as competências e as práticas de diversidade. Assim, workshops foram realizados e novos programas e práticas de gestão de pessoas foram elaborados. Um

Tabela 1 - Composição dos funcionários da ALPHA do Brasil

\begin{tabular}{|c|c|c|c|c|c|}
\hline GÊNERO & $\%$ & RAÇA & $\%$ & IDADE & $\%$ \\
\hline Feminino & 8,7 & Branco & 83,1 & 15 a 20 anos & 3,7 \\
\hline \multirow[t]{4}{*}{ Masculino } & 91,3 & Negro & 15,8 & 21 a 30 anos & 27,2 \\
\hline & & Oriental & 1,0 & 31 a 40 anos & 46,6 \\
\hline & & & & 41 a 50 anos & 19,1 \\
\hline & & & & Mais de 50 anos & 3,0 \\
\hline
\end{tabular}


exemplo foi o programa de liderança, desenhado para trabalhar essas questões com os empregados, em todos os níveis da organização.

Com referência à comunicação, ponto importante do programa na matriz, os avanços têm sido graduais, pois se observou que, se não houver resultados práticos a serem divulgados, o processo de comunicação cairá no vazio e o programa em descrédito. A forma utilizada para comunicar o programa são encontros em que as pessoas discutem o tema e se sensibilizam para as barreiras invisíveis existentes na organização.

Estando em pauta o programa de diversidade há três anos, a empresa criou indicadores, diferentes das tradicionais cotas praticadas nos EUA, para mensurar sua eficácia. Esses indicadores devem estar relacionados aos objetivos do negócio. Definiram-se, assim, indicadores de input (relacionados, por exemplo, ao recrutamento de uma força de trabalho diversificada, job rotation e assim por diante) combinados com indicadores de output (resultados de vendas, atendimento a clientes, novos produtos, resultados da pesquisa interna de clima). O programa tem sido avaliado positivamente pela empresa, tanto no Brasil como nos Estados Unidos, que passaram inclusive a rever certas estratégias lá adotadas.

A nosso ver, o caso da ALPHA exemplifica a posição assumida por empresas brasileiras a respeito da questão da diversidade cultural. Embora o programa tenha sido introduzido por incentivo da matriz, houve a necessidade de se desenvolver uma abordagem local, adaptada à realidade brasileira, ou seja, se o conceito foi globalmente definido, a prática é concebida localmente e tem que ser consistente com a estratégia do negócio. A metodologia da pesquisa-ação se mostrou adequada para esse trabalho.

\section{COMENTÁRIOS FINAIS}

Em um país como o Brasil, com uma sociedade heterogênea e com muitas desigualdades sociais, o tema da diversidade cultural assume relevância. Trabalhar e denunciar o imaginário popular de uma sociedade livre de preconceitos, cujo acesso às posições no sistema educacional e no mercado de trabalho é aberto a todos, é importante para fazer avançar essas questões num país que se quer democrático.

Do ponto de vista das empresas, entretanto, o foco precisa ser menos ideológico e mais estratégico, para que programas dessa natureza frutifiquem. Não nos parece também interessante equacionar essa questão com a abordagem legal desenvolvida em países da América do Norte, ou seja, estabelecendo, por exemplo, cotas para garantir o acesso das minorias aos empregos. A nosso ver, um caminho promissor é ampliar o foco de atuação, incorporando ao programa objetivos econômicos e sociais, mostrando, por exemplo, como uma política de gestão da diversidade cultural pode atrair e desenvolver novas competências, adicionando valor ao negócio.

Em um país em que as empresas enfrentam os desafios da competitividade e da onda de fusões e aquisições, trazendo para o cenário doméstico novos jogadores, com diferentes culturas, essa diversidade é um tema bastante atual. $\bigcirc$
REFERÊNCIAS BIBLIOGRÁFICAS

AGÓCS, C., BURR, C. Employment equity, Affirmative Action and managing diversity: assessing the differences. International Journal of Manpower, v. 17, n. 4/5, 1996.

COX, T. Cultural diversity in organizations: theory, research and practice. San Francisco : Berrett-Koehler Publishers, 1994.

JAIN, H. Efficiency and equity in employment: equity/ Affirmative Action program in Canada, USA, UK, South Africa, Malaysia and India in developing competitiveness and social justice. In: WORLD CONGRESS, 11., 1998, Bologne. Proceedings... Bologne, 1998.
KNOMO, S., COX, T. Diverse identities in organizations. In: CLEGG, S., HARDY, C., NORD, W. Handbook of Organization Studies. London : Sage, 1996.

MAMMAN, A. Employee intercultural effectiveness in a multicultural workplace: theoretical propositions, strategies and direction for future research. The International Journal of Human Resource Management, v. 6, n. 3, Sept. 1995.

MINISTÉRIO DO TRABALHO DO BRASIL. Relatório do encontro tripartite sobre a implementação de políticas voltadas à diversidade. São Paulo, out. 1996.
NILSON, J. Developing a diversity program: as community demographics change and healthcare organizations extend their geographic reach, many providers are serving and trying to attract a population that is more diverse than ever before. Healthcare Executive, July/Aug. 1997.

SUBBARAO, A. V. Managing workforce diversity: an innovation or an evolution? In: WORLD CONGRESS OF INTERNATIONAL INDUSTRIAL RELATIONS ASSOCIATION, 10., May/June 1995, Washington, DC, USA.

THOMAS, D. Making differences matter: a new paradigm for managing diversity. Harvard Business Review, v. 74, n. 5, Sept./ Oct. 1996. 